\title{
THE LIGHTSHIP MASS CALCULATION MODEL OF A MERCHANT SHIP BY EMPIRICAL METHODS
}

\author{
Vedran Slapničar'), Katarina Zadro ${ }^{2)}$, \\ Viktor Ložar'), Ivo Ćatipović1) \\ 1) University of Zagreb (Croatia) \\ ${ }^{2)}$ Zagreb (Croatia)
}

\begin{abstract}
Estimating the lightship mass is an important factor in the early stage of ship design given its impact on shipbuilding costs. The mass of the hull and equipment, as well as its distribution, affects the hull strength, deadweight, and stability of the ship. Furthermore, a good estimate of the lightship mass in the preliminary phase is very important for defining the construction costs as accurately as possible. As the time available to the designer in the conceptual or preliminary phase of ship design is often limited, the methods used to determine the lightship mass must be reliable, fast, and effective. The paper presents and analyzes methods for estimating the lightship mass that are based on empirical data of built ships. Several empirical methods were combined and calibrated to establish the leastsquares method which combination gives the value of the lightship mass closest to the one given in the collected database for three types of merchant ships: tankers, bulk carriers, and container ships. The paper presents the results of the calculations of the masses of hull steel, outfitting, machinery, and superstructure. It can be concluded that the presented model for all three types of merchant ships gives satisfactory results.

Keywords: Preliminary ship design; database; lightship mass calculation; regression analysis; empirical methods; calibration; merchant ships; bulk carriers; container ships; tankers
\end{abstract}

\section{Introduction}

Defining the lightship mass is an important factor in ship design for several reasons. The mass of the hull and outfitting, as well as its distribution, affects the hull strength, deadweight, and stability of the ship. A good estimate of the lightship mass in the preliminary phase is very important for defining the construction costs as accurately as possible. Ensuring safety conditions, deadweight and achieving the required speed are important requirements that are interdependent. The mass of the hull directly affects the deadweight, but also 
the safety in terms of meeting the required hull section modulus and ensuring transverse and local strength.

The lightship mass is defined in the conceptual and preliminary design phase of the ship. The working hours spent in the mentioned phases are small concerning the total required working hours for all phases of the project. Additional efforts in the phase of the conceptual or preliminary project will not significantly affect the total number of working hours but can therefore significantly affect the total cost of the project and its performance.

Thus, estimating the costs of the lightship mass is significant because it affects the estimation of the total costs of the construction. The lightship mass is determined by the empirical equations that are used in the preliminary design phase. Originally, these equations are given in detail in (Watson 1998; Schneekluth \& Bertram 1998) while in (SNAME 2003; Papanikolaou 2014) some of them are given with examples.

Belamarić (1998) gives an overview of built tankers in a domestic shipyard while (Gugić et al. 2002) gives the volume dependencies of cargo and ballast tanks related to deadweight, displacement, and main dimensions, based on the database of 111 crude oil tankers built in the period 1991-2021. The proposed model for preliminary design (Gugić et al. 2002) of the crude oil tankers is based on the regression equations through which the lightship mass can be derived. Studying the subject of lightship mass estimation, it can be concluded that there are no papers dealing with this theme in recent times. Existing empirical methods are based on ships being built many years ago, and have been developed by both individual authors and classification societies. Methods that assume in the preliminary stage that the general plan, by which the lightship mass is calculated in more detail, is known are not the subject of this paper.

When designing a ship, the designer strives to achieve as small as possible lightship mass to reduce the cost and to satisfy the deadweight defined by the project requirement. The sum of the lightship mass and the deadweight makes the ship displacement. The lightship mass is determined for three types of merchant ships: bulk carriers, container ships, and tankers. The reason for such a choice is that the demand for these types of merchant ships is the greatest. A database of 110 ships was created containing the most important features of the ship. The shipbuilding journal Significant Ships ${ }^{1)}$ served as a source of data. Figure 1 shows the collected ships as a function of the deadweight/displacement ratio. This is done for all three groups of merchant ships, taking into account the deadweight at the maximum draft. 


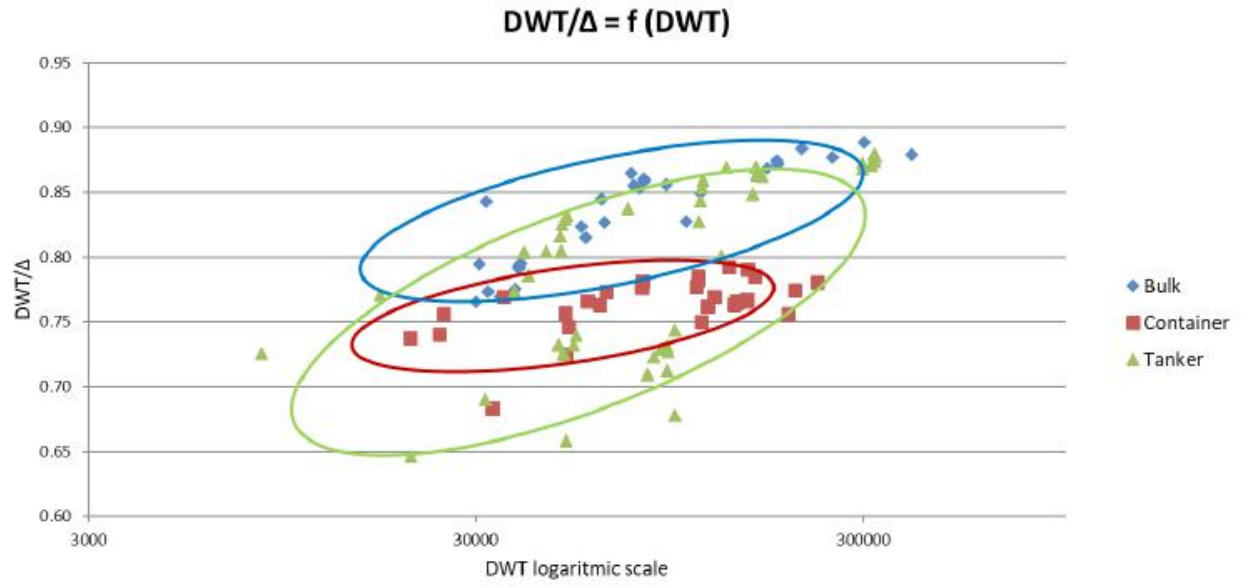

Figure 1. Database - Deadweight/dependence ratio

In addition to diagrams showing the dependencies of main features important for the ship design, it is useful to know the range of individual features or the range of feature ratios for each type of merchant ship. In this way, a designer can easily check whether a design process is on the right path. Table 1 contains the features of the database that represent an important factor in the preliminary ship design phase.

Table 1. Features of the database

\begin{tabular}{|l|c|c|c|}
\hline \multicolumn{1}{|c|}{ Ship type } & L / B & B / T & L / V $^{\mathbf{3}}$ \\
\hline Bulk & $5.46-9.24$ & $2.16-3.17$ & $4.64-6.04$ \\
\hline Container & $5.37-7.80$ & $2.33-3.73$ & $5.01-6.26$ \\
\hline Tanker & $5.28-6.98$ & $2.26-3.85$ & $4.32-5.75$ \\
\hline Ship type & Cb & DWT [t] & Admiralty coeff. \\
\hline Bulk & $0.78-0.90$ & $29984-398595$ & $477-919$ \\
\hline Container & $0.62-0.73$ & $20326-228600$ & $534-972$ \\
\hline Tanker & $0.71-0.87$ & $8404-323190$ & $292-1088$ \\
\hline
\end{tabular}

\section{Lightship mass}

The displacement of a ship is the sum of the lightship mass and the deadweight (formula 1). Deadweight is divided into payload (paid cargo), and consumables (water, fuel, lubricant), ballast water, crew, and provisions and stores. The main task of a merchant ship is to make a profit and that depends on the cargo amount that the ship can carry. If the total displacement of the ship cannot be increased, the designer must reduce the lightship mass to a minimum. The lightship mass can be optimized by various methods such as selecting the most suitable dimensions of the new ship, using lighter materials in construction, reducing the amount of equipment 
as much as possible, the best mass-to-power ratio when choosing machinery, and layout arrangement to maximize the cargo capacity.

$$
\Delta_{\mathrm{T}}=\Delta_{\mathrm{LS}}+D W T
$$

where:

$$
\begin{aligned}
& \Delta_{\mathrm{T}} \text { - Displacement [t], } \\
& \Delta_{\mathrm{LS}} \text { - Lightship Mass [t], } \\
& D W T \text { - Deadweight [t]. }
\end{aligned}
$$

The lightship mass in this paper is considered as follows:

$$
\begin{aligned}
& \Delta_{\mathrm{LS}} \\
& =\Delta_{\mathrm{ST} \text { hull }}+\Delta_{\mathrm{ST} \text { superstructure }} \\
& +\Delta_{\text {OUT }}+\Delta_{\mathrm{M}}
\end{aligned}
$$

where:

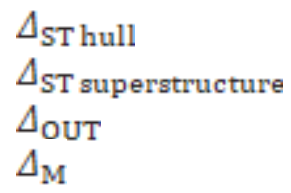

$$
\begin{array}{r}
\text { Steel Hull }[\mathrm{t}] \text {, } \\
\text { St. Superstructure [t], } \\
\text { Outfitting [t], } \\
\text { Machinery [t]. }
\end{array}
$$

Mass of steel includes all steel used in the construction of the ship in the form of plates, girders, frames, bulkheads, hatch covers, etc. Mass of outfitting includes the mass of all items installed on the ship such as doors, furniture, lighting, etc. Mass of machinery includes the mass of all machinery on board, appliances, pipelines, switchboards, etc. The last thing that should be taken into account to make up the lightship mass is the ship margin.

As already mentioned in the introductory part of the paper, the estimation of lightship mass is an important factor in the early stage of ship design considering its impact on shipbuilding costs. As the time available to the designer in the conceptual or preliminary phase of ship design is often limited, the methods used to determine the lightship mass must be reliable, fast, and effective. Therefore, the methods based on empirical data of built ships used in this paper for estimating the lightship mass are stated in Chapter 2.1.

\section{Empirical methods for estimating hull steel mass}

1) J.M. MURRAY (1965) (Schneekluth et al. 1998)

A method used for calculation of the hull steel mass of bulk carriers for lengths between perpendiculars of 72 and 225 meters. 


$$
\begin{aligned}
& \Delta_{\text {ST hull }} \\
& =\frac{26.6 * 10^{-3} * L^{1.65} *\left(B+D+\frac{T}{2}\right) *\left(0.5 C_{b}+0.4\right)}{0.8}
\end{aligned}
$$

2) S. SATO (1967) (Schneekluth et al. 1998)

A method used for calculation of the hull steel mass of large ships (mostly tankers).

$$
10^{5} * \Delta_{\mathrm{ST} \text { hull }}=\left(\frac{C_{b}}{0.8}\right)^{\frac{1}{3}} *\left\{5.11 * L^{3.3} * \frac{B}{D}+\left[\left(2.56 * L^{2}\right) *(B+D)^{2}\right]\right\}
$$

3) WATSON \& GILFILLAN (Watson 1998)

A method that gives a general formula applicable to all three types of ships.

$$
\begin{aligned}
& \Delta_{\mathrm{ST}}=\Delta_{\mathrm{ST} 1} *\left[1+0.5 *\left(C_{b 1}-C_{b}\right)\right] \\
& C_{b 1}=C_{b}+\left(1-C_{b}\right) *\left(\frac{0.8 * D-T}{3 * T}\right) \\
& \Delta_{\mathrm{ST} 1}=K * E^{1.36} \\
& E=L *(B+T)+0,85 *(D-T) * L
\end{aligned}
$$

Table 2 gives the values of the coefficient $\mathrm{K}$ for the type of merchant ship.

Table 2. The value of the coefficient $\mathrm{K}$ for the particular type of merchant ship

\begin{tabular}{|l|c|c|}
\hline Ship type & The value of K & For E \\
\hline Tanker & $0.029-0.035$ & $1500<\mathrm{E}<40000$ \\
\hline Chemical tanker & $0.036-0.037$ & $1900<\mathrm{E}<2500$ \\
\hline Bulker & $0.029-0.032$ & $3000<\mathrm{E}<15000$ \\
\hline Container & $0.033-0.040$ & $6000<\mathrm{E}<13000$ \\
\hline
\end{tabular}

4) HARVALD \& JENSEN (1992) (Schneekluth et al. 1998)

A method used to calculate the hull steel mass applicable to all three types of merchant ships.

$$
\begin{aligned}
& \Delta_{\mathrm{ST} \text { hull }}=(L * B * D) * C_{\mathrm{S}} \\
& C_{\mathrm{S}}=C_{\mathrm{S} 0}+0,64 e^{-\left(0.5 * u+0.1 * u^{2.45}\right)}
\end{aligned}
$$


$u=\log _{10}\left(\frac{\Delta}{100 t}\right)$

$C_{\mathrm{So}}=0.0700 \rightarrow$ bulker, container

$C_{\text {so }}=0.0753 \rightarrow$ tanker

$C_{\mathrm{so}}=0.0645 \rightarrow \mathrm{VLCC}$ tanker

\section{Empirical methods for estimating the mass of steel superstructures}

1) WATSON \& GILFILLAN (Watson 1998)

A method used to calculate the mass of steel superstructure for all three types of merchant ships.

$$
\begin{aligned}
& \Delta_{\mathrm{ST} \text { superstructure }}=\Delta_{\mathrm{ST} 1} *\left[1+0.5 *\left(C_{b 1}-C_{b}\right)\right] \\
& C_{b 1}=C_{b}+\left(1-C_{b}\right) *\left(\frac{0.8 * D-T}{3 * T}\right) \\
& \Delta_{\mathrm{ST} 1}=K * E^{1.36} \\
& E=0.85 * \sum l * h \\
& \text { where: } \\
& l_{\text {- superstructurelength }[\mathrm{m}] \text { and }} \\
& { }_{\text {- superstructure height }[\mathrm{m}] .}
\end{aligned}
$$

\section{Empirical methods for estimating the outfitting mass}

1) H. SCHNEEKLUTH (Schneekluth et al. 1998)

The method used for calculation of the outfitting mass for all three types of merchant ships.

$$
\begin{array}{ll}
\Delta_{\text {OUT }}=K * L * B \quad(16) & \\
K=0.34-0.38 \mathrm{t} / \mathrm{m}^{2} & \rightarrow \text { container } \\
K=0.22-0.25 \mathrm{t} / \mathrm{m}^{2} & \rightarrow \text { bulker L } \sim 140 \mathrm{~m} \\
K=0.17-0.18 \mathrm{t} / \mathrm{m}^{2} & \rightarrow \text { bulker L } \sim 250 \mathrm{~m} \\
K=0.25 \mathrm{t} / \mathrm{m}^{2} & \rightarrow \text { tanker } \sim_{150 \mathrm{~m}} \\
K=0.17 \mathrm{t} / \mathrm{m}^{2} & \rightarrow \text { tanker } \sim_{300 \mathrm{~m}}
\end{array}
$$

2) WATSON \& GILFILLAN (Watson 1998)

A method applicable to all three types of the ship when calculating the outfitting mass.

$$
\Delta_{\mathrm{OUT}}=C_{\mathrm{o}} \cdot L \cdot B
$$


Table 3 shows the values of the outfitting coefficient $C_{\mathrm{o}}$.

Table 3. Outfitting coefficient values $C_{\mathrm{o}}$

\begin{tabular}{|l|c|c|}
\hline Ship type & Length range $[\mathbf{m}]$ & Coefficient value \\
\hline Bulker & $120-150$ & $0.250-0.230$ \\
\hline Bulker & $150-200$ & $0.230-0.200$ \\
\hline Bulker & $200-250$ & $0.200-0.170$ \\
\hline Bulker & $250-280$ & $0.170-0.160$ \\
\hline Bulker & $280-370$ & $0.160-0.130$ \\
\hline Container & $155-290$ & $0.320-0.330$ \\
\hline Container & $290-425$ & $0.330-0.340$ \\
\hline Tanker & $100-150$ & $0.298-0.280$ \\
\hline Tanker & $150-250$ & $0.280-0.245$ \\
\hline Tanker & $250-350$ & $0.245-0.190$ \\
\hline
\end{tabular}

\section{Empirical methods for estimating the mass of a machinery}

Methods that consider the mass of the diesel main propulsion machinery and the mass of all auxiliary machinery, used for all three types of selected merchant ships, are given by formulas (18-20).

1) SILVER \& DAWSON

$\Delta_{\mathrm{M}}=\frac{M C R}{30}+1000$

2) CB BARRASS (1997) (Barrass 2004)

$$
\Delta_{\mathrm{M}}=0.075 \mathrm{MCR}+300
$$

3) MUNRO-SMITH (Munro-Smith 1975)

$$
\Delta_{\mathrm{M}}=\frac{M C R}{10}+200
$$

4) WATSON \& GILFILLAN (Watson 1998)

A method that comprises in the formula a part for the mass of the diesel main propulsion machinery and the mass of auxiliary machinery depending on the type of merchant ship. 
$\Delta_{\mathrm{M}}=\sum_{i} 12\left[\frac{M C R}{R P M}\right]^{0.84}+\Delta_{\mathrm{AUX}}$

where:

$M C R$ - maximum continuous rating in $\mathrm{kW}$,

$R P M_{\text {- engine revolutions per minute, }}$

$\Delta_{\mathrm{AUX}}$ - mass of auxiliary machinery in $\mathrm{t}$.

$\Delta_{\mathrm{AUX}}=0.69 * M C R^{0.7}$

$\Delta_{\mathrm{AUX}}=0.72 * M C R^{0.7} \rightarrow$ bulker

In the next chapter, it will be examined which combination of empirical methods gives the lightship mass, closest to the one given in the publication ${ }^{1)}$ for all three types of merchant ships.

\section{Calculation of the lightship mass}

The aim of the calculation in this chapter was to examine which combination of empirical methods gives the value of the lightship mass, closest to the one given in the database collected for 30 bulk carriers, 30 container ships, and 50 tankers. Calculations of the masses of hull steel, outfitting, machinery, and superstructure were carried out. 24 possible combinations of empirical methods were made after which the least-squares method was used to determine which combination gives the best results in terms of comparing the obtained values with the ones published in the journal Significant Ships ${ }^{1)}$. The function, which is used in the least-squares method, calculates the statistics for a straight line that explains the relation between the independent variable and the dependent variable and returns an array describing the line.

\section{Bulk carriers}

The results of the least-squares method for bulk carriers are shown in Table 4 and were obtained by a combination of formulas $3,5,9,12,16,17,18,19,20$, and 21 .

Table 4. Results of the least-squares method for bulk carriers

\begin{tabular}{|c|c|c|c|c|c|}
\hline \multicolumn{6}{|l|}{$\mathrm{k}$} \\
\hline 1 & 2 & 3 & 4 & 5 & 6 \\
\hline 0.958 & 0.949 & 0.962 & 0.953 & 0.969 & 0.960 \\
\hline 7 & 8 & 9 & 10 & 11 & 12 \\
\hline \begin{tabular}{|l|}
0.961 \\
\end{tabular} & 0.952 & 0.979 & 0.969 & 0.984 & 0.975 \\
\hline 13 & 14 & 15 & 16 & 17 & 18 \\
\hline 0.991 & 0.981 & 0.982 & 0.972 & 1.056 & 1.048 \\
\hline 19 & 20 & 21 & 22 & 23 & 24 \\
\hline 1.064 & 1.053 & 1.072 & 1.061 & 1.062 & 1.051 \\
\hline
\end{tabular}


The results vary in a range from $0.949-1.072$, while the combination that gives the best result $\mathrm{k}=0.991$ corresponds to the following combination:

$$
\begin{aligned}
& \Delta_{\mathrm{LS}-\mathrm{BULKER}} \\
& =\Delta_{\mathrm{ST}} \text { hull Harvald\&Jensen } \\
& +\Delta_{\mathrm{M} \text { Barrass }} \\
& +\Delta_{\mathrm{ST} \text { superstructure Watson\& Gilfillan }}
\end{aligned}
$$

To determine the calibrated value of the lightship mass it is necessary to multiply the coefficient obtained by the least-squares method with the lightship mass obtained by a combination of empirical methods:

$$
\begin{aligned}
& \Delta_{\text {LS-BULKER-CALIBRATED }} \\
& =k \cdot \Delta_{\text {LS-BULKER }}
\end{aligned}
$$

For the designer, in the preliminary phase of the ship design, it is useful to know the dependence of the lightship mass related to the length of the ship. Figure 2 shows the above-mentioned dependence for the mass given ${ }^{1)}$ and for the calibrated lightship mass.

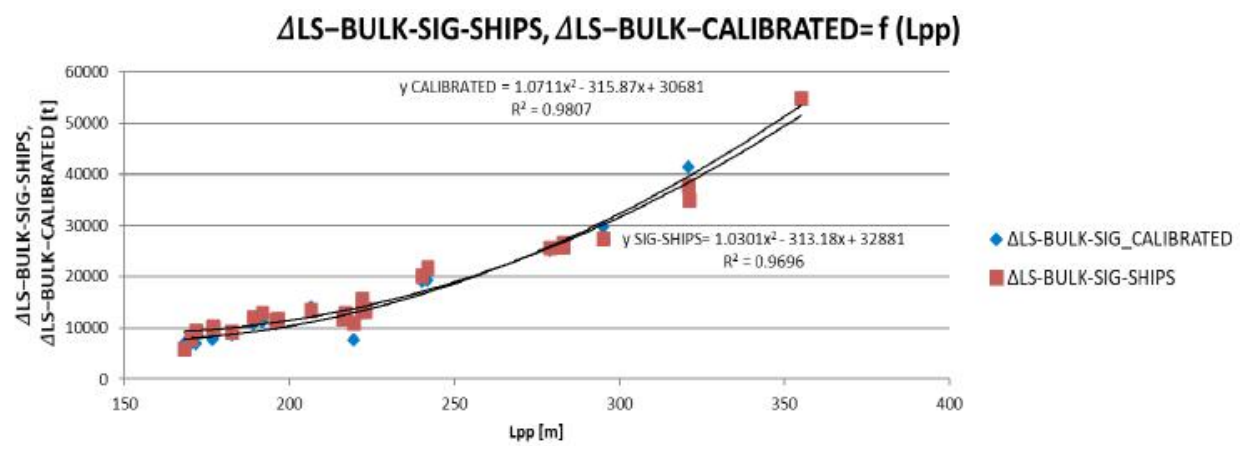

Figure 2. Dependence of the lightship mass for the bulk carriers related to the length of the ship between the perpendiculars

The formula below gives the dependence of the lightship mass for the bulk carriers related to the length of the ship between the perpendiculars, expressed as a polynomial of 2 nd degree: 
$\Delta_{\text {LS-BULKER-CALIBRATED }}$

$$
\begin{aligned}
& =1.0711 * L_{P P}^{2} \\
& -315.87 * L_{P P} \\
& +30681
\end{aligned}
$$

\section{Container ships}

The results of the least-squares method for container ships are shown in Table 5 and were obtained by a combination of formulas $4,5,9,12,16,17,18,19,20$, and 21 .

Table 5. Results of the least-squares method for container ships

\begin{tabular}{|c|c|c|c|c|c|}
\hline \multicolumn{7}{|c|}{$\mathrm{k}$} \\
\hline $\mathbf{1}$ & $\mathbf{2}$ & $\mathbf{3}$ & $\mathbf{4}$ & $\mathbf{5}$ & $\mathbf{6}$ \\
\hline 0.895 & 0.887 & 0.925 & 0.916 & 0.902 & 0.893 \\
\hline $\mathbf{7}$ & $\mathbf{8}$ & $\mathbf{9}$ & $\mathbf{1 0}$ & $\mathbf{1 1}$ & $\mathbf{1 2}$ \\
\hline 0.882 & 0.874 & 0.946 & 0.936 & 0.980 & 0.969 \\
\hline $\mathbf{1 3}$ & $\mathbf{1 4}$ & $\mathbf{1 5}$ & $\mathbf{1 6}$ & $\mathbf{1 7}$ & $\mathbf{1 8}$ \\
\hline 0.954 & 0.944 & 0.932 & 0.923 & 0.890 & 0.881 \\
\hline $\mathbf{1 9}$ & $\mathbf{2 0}$ & $\mathbf{2 1}$ & $\mathbf{2 2}$ & $\mathbf{2 3}$ & $\mathbf{2 4}$ \\
\hline 0.919 & 0.910 & 0.897 & 0.888 & 0.877 & 0.869 \\
\hline
\end{tabular}

The results vary in a range from $0.869-0.980$, while the combination that gives the best result $\mathrm{k}=0.980$ corresponds to the following combination:

$$
\begin{aligned}
& \Delta_{\text {LS-CONT }} \\
& =\Delta_{\text {ST hull Harvald\&Jensen }} \\
& +\Delta_{\text {OUT Watson\&Gilfillan }} \\
& \Delta_{\text {ST superstructure Watson\&Gilf illan }}
\end{aligned}
$$

To determine the calibrated value of the lightship mass it is necessary to multiply the coefficient obtained by the least-squares method with the lightship mass obtained by a combination of empirical methods:

$$
\begin{aligned}
& \Delta_{\mathrm{LS}-\mathrm{CONT}-\mathrm{CALIBRATED}} \\
& =k * \Delta_{\mathrm{LS}} \text {-CONT }
\end{aligned}
$$

Figure 3 shows the stated dependence for the mass given in (Significant Ships 2006 - 2019) and for the calibrated lightship mass for the container ships. 


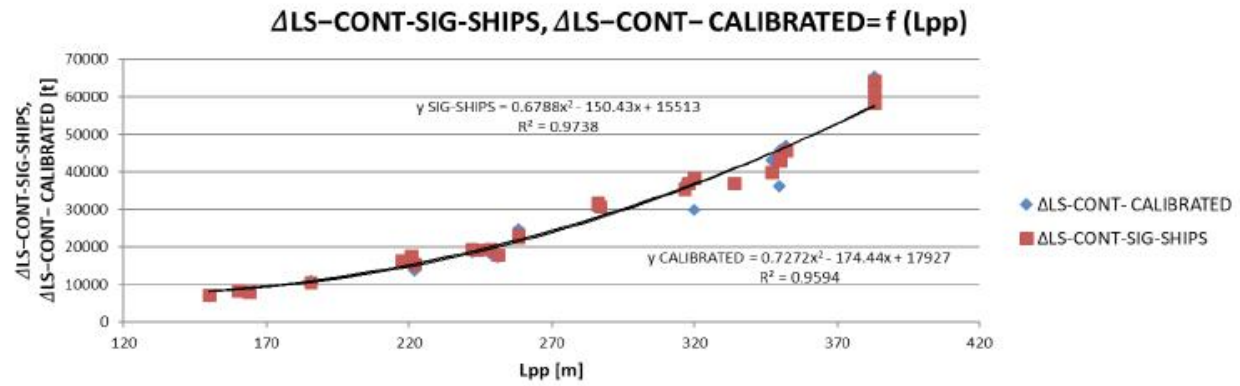

Figure 3. Dependence of the lightship mass for the container ships related to the length of the ship between the perpendiculars

The formula below gives the dependence of the lightship mass for the container ships related to the length of the ship between the perpendiculars, expressed as a polynomial of 2 nd degree:

$$
\begin{aligned}
\Delta_{\text {LS-CONT-CALIBRATED }} \\
=0.7272 * L_{P P}^{2} \\
-174.44 * L_{P P} \\
+17927
\end{aligned}
$$

\section{Tankers}

\begin{tabular}{|c|c|c|c|c|c|}
\hline \multicolumn{6}{|l|}{$\mathrm{k}$} \\
\hline 1 & 2 & 3 & 4 & 5 & 6 \\
\hline 1.081 & 1.106 & 1.099 & 1.125 & 1.094 & 1.120 \\
\hline 7 & 8 & 9 & 10 & 11 & 12 \\
\hline 1.081 & 1.106 & 1.017 & 1.038 & 1.032 & 1.054 \\
\hline 13 & 14 & 15 & 16 & 17 & 18 \\
\hline 1.028 & 1.050 & 1.016 & 1.038 & 1.086 & 1.110 \\
\hline 19 & 20 & 21 & 22 & 23 & 24 \\
\hline 1.102 & 1.127 & 1.099 & 1.124 & 1.085 & 1.109 \\
\hline
\end{tabular}

The results of the least-squared method for tankers are shown in Table 6 and were obtained by a combination of formulas $4,5,9,12,16,17,18,19,20$, and 21 .

Table 6. Results of the least-squares method for tankers 
The results vary in a range from $1.016-1.127$, while the combination that gives the best result $\mathrm{k}=1.016$ corresponds to the following:

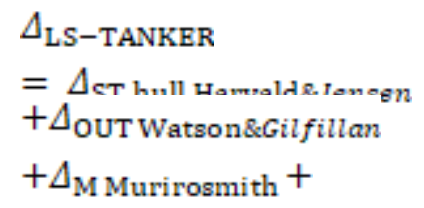

To determine the calibrated value of the lightship mass it is necessary to multiply the coefficient obtained by the least-squares method with the lightship mass obtained by a combination of empirical methods:

$$
\begin{aligned}
& \Delta_{\mathrm{LS}-\mathrm{TANKER}-\mathrm{CALIBRATED}} \\
& =k * \Delta_{\mathrm{LS}-\mathrm{TANKER}}
\end{aligned}
$$

Figure 4 shows the stated dependence for the mass given ${ }^{1)}$ and for the calibrated lightship mass for tankers.

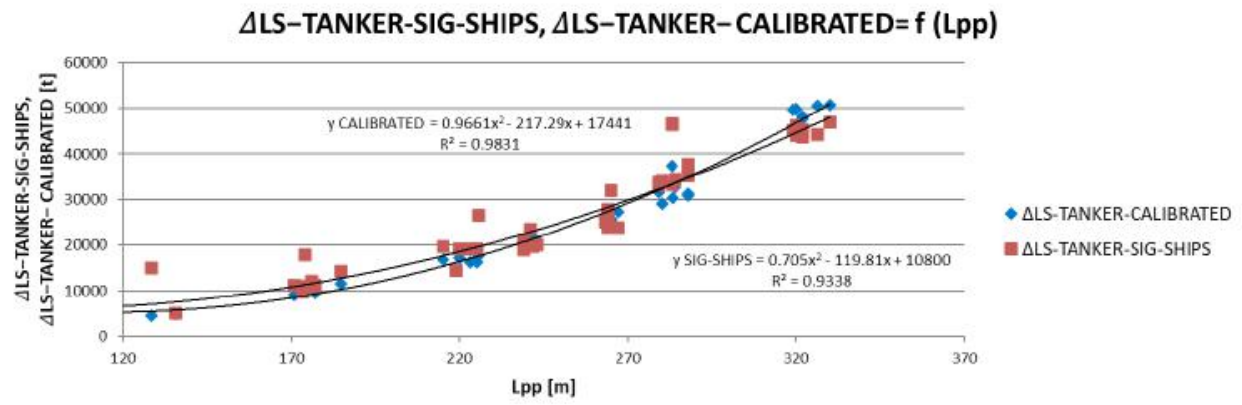

Figure 4. Dependence of the lightship mass for the tankers related to the length of the ship between the perpendiculars

The formula below gives the dependence of the lightship mass for the tankers related to the length of the ship between the perpendiculars, expressed as a polynomial of 2nd degree:

$$
\begin{aligned}
& \Delta_{\text {LS-TANKER-CALIBRATED }} \\
&=0.9661 * L_{P P}^{2} \\
&-217.29 * L_{P P} \\
&+17441
\end{aligned}
$$




\section{Dependency diagrams of features important in the ship design process}

The designer needs to know the dependence of the lightship mass on the ships' displacement since these two features must be determined while the deadweight is defined by the design requirement. Figure 5 shows the above-stated dependence for bulk carriers, container vessels, and tankers. LNG tankers are shown (10 ships) in the diagram separately from other types of tankers ( 40 ships) due to their difference in features compared to other types. The lightship mass shown in the diagram is the calibrated value.

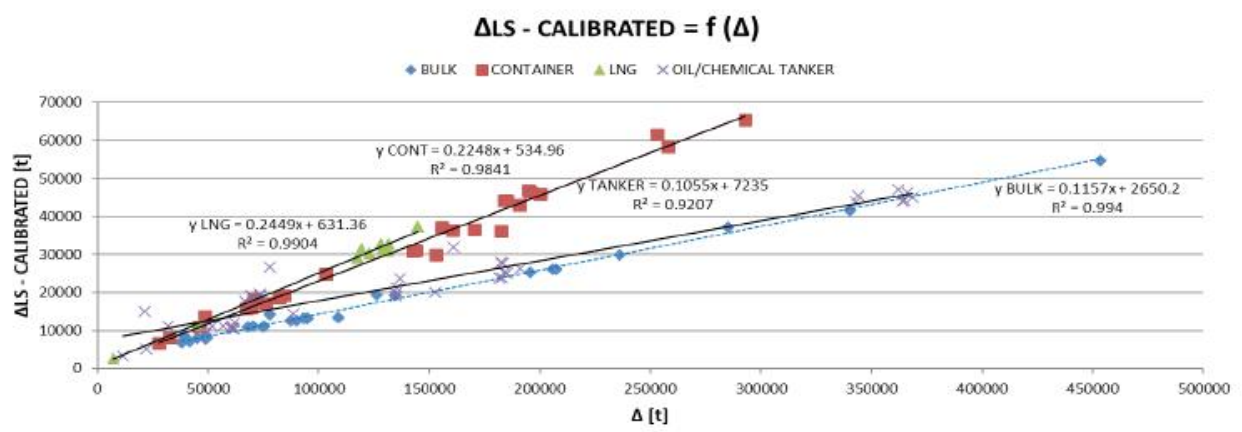

Figure 5. Dependence of the calibrated lightship mass related to the displacement

Useful data in the ship design is the $\mathrm{K}$ value which represents the ratio of the lightship mass and the main dimensions of the ship (length, width, and height) and shows this ratio related to the length of the ship between the perpendiculars (Figure 6). The value of the feature $\mathrm{K}$ is obtained by the following formula (Papanikolaou, 2014):

$$
K=\frac{\Delta_{\mathrm{LS}}}{L * B * D}
$$

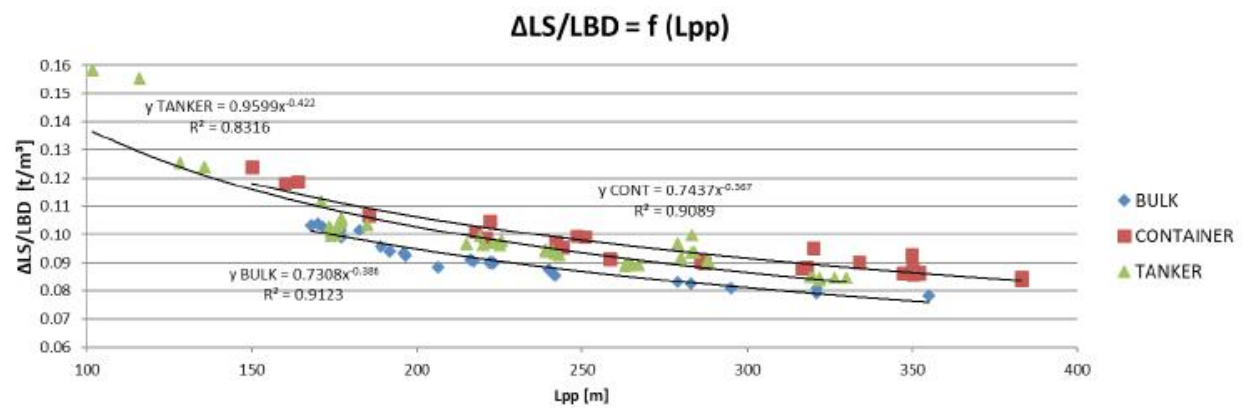

Figure 6. Dependence of the feature K related to the length of the ship between the perpendiculars 
To estimate the lightship mass, it is important to know the ratio of the mass of steel, outfitting, and machinery part related to the lightship mass, as well as the ratio of the deadweight at maximum draft and displacement of the ship. Ratios were calculated and given for each ship type from the database. The ratio ranges are shown in Table 7.

Table 7. Ratio ranges for each type of merchant ship

\begin{tabular}{|l|c|c|c|c|c|}
\hline Ship type / Range & DWT [t] & DWT / $[\%]$ & $\Delta S T / \Delta$ LS [\%] & $\Delta$ OUT / $\Delta$ LS [\%] & $\Delta \mathrm{M} / \Delta$ LS [\%] \\
\hline Bulk & $29984-398595$ & $76.54-88.83$ & $75.79-91.41$ & $6.10-14.85$ & $3.36-10.30$ \\
\hline Container & $20326-228600$ & $68.32-79.28$ & $63.49-85.54$ & $12.06-18.97$ & $4.42-20.82$ \\
\hline Tanker & $8404-323190$ & $64.62-87.88$ & $59.32-86.21$ & $8.23-20.24$ & $3.49-18.96$ \\
\hline
\end{tabular}

\section{Conclusions}

This paper covers the initial phase of ship design where the designer needs lightship mass information. Therefore, a database for three selected types of merchant ships was created to conduct regression analysis. Defining the lightship mass is an important factor in ship design for several reasons. The mass of the hull and outfitting, as well as its distribution, affects the hull strength, deadweight and stability of the ship. Furthermore, a good estimate of the lightship mass in the preliminary phase is important for defining the construction costs as accurately as possible. Comparing the values of the lightship masses obtained by empirical methods with the values given in the journal Significant Ships, it can be concluded that for all three types of merchant ships the selected and calibrated empirical methods give satisfactory results. Given the fact that the designer often has limited time available for defining the features in the initial stages of design, the methods used to determine these features must be fast, simple, and efficient. The empirical methods used in this paper have been proven in satisfying the stated conditions.

\section{NOTES}

1. Royal Institution of Naval Architects, 2006 - 2019. London: Significant Ships.

\section{REFERENCES}

Watson, 1998. DGM, Practical Ship Design. Oxford: Elsevier Science Ltd.

Schneekluth, H., Bertram, V., 1998. Ship Design for Efficiency and Economy. $2^{\text {nd }}$ edition. Oxford: Butterworth-Heinemann.

SNAME, 2003. Ship Design and Construction. New Jersey, MG Parsons:

Parametric Design, Chapter 11. 
Papanikolaou, A., 2014. Ship Design - Methodologies of Ship Design. Springer.

Belamarić, I., 1998. Ship and Entropy, Literary circle. Split, Croatia [in Croatian].

Gugić, D., Slapničar, V., Brigić, J., 2002. A Contribution to Preliminary Crude Oil Tanker Design. In: Symposium on Theory and Practice of Shipbuilding SORTA. Trogir, Croatia, 53-61.

Barrass, C.B., 2004. Ship Design and Performance for Masters and Mates. Elsevier B-H.

Munro-Smith, R., 1975. Elements of Ship Design. Marine Media Management Ltd.

https://orcid.org/0000-0002-3175-2542

Faculty of Mechanical Engineering and Naval Architecture

University of Zagreb

Zagreb, Croatia

E-mai: vedran.slapnicar@fssb.hr

$\triangle$ Katarina Zadro

https://orcid.org/0000-0001-6418-4513.

Zagreb, Croatia

E-mai: katarinazadro@hotmail.com

$\triangle$ Viktor Ložar

https://orcid.org/0000-0001-6718-8245

Faculty of Mechanical Engineering and Naval Architecture

University of Zagreb

Zagreb, Croatia

E-mai: viktor.lozar@fssb.hr

$\triangle$ Ivo Ćatipović

https://orcid.org/0000-0001-8385-7736

Faculty of Mechanical Engineering and Naval Architecture

University of Zagreb

Zagreb, Croatia

E-mai: ivan.catipovic@fsb.hr 